\title{
Theoretical Insights into Three Types of Oxidized Starch-Based Adhesives: Chemical Stability, Water Resistance, and Shearing Viscosity from a Molecular Viewpoint
}

\author{
Liang Junxi, Su Qiong, Zhao Yamin, and Wang Yanbin \\ Gansu Key Laboratory of Environmental Friendly Composites and Biomass Utilization, College of Chemical Engineering, \\ Northwest University for Nationalities, Lanzhou, Gansu 730030, China
}

Correspondence should be addressed to Liang Junxi; xbmujxliang@126.com

Received 4 November 2015; Revised 10 March 2016; Accepted 26 May 2016

Academic Editor: Yves Grohens

Copyright (C) 2016 Liang Junxi et al. This is an open access article distributed under the Creative Commons Attribution License, which permits unrestricted use, distribution, and reproduction in any medium, provided the original work is properly cited.

\begin{abstract}
To better understand the origin and difference associated with chemical stability, water resistance, and shearing viscosity of three types of different oxidized modified starch-based adhesives, a detailed theoretical investigation from a molecular viewpoint has been performed using the AM1 semiempirical level and the DFT-B3LYP level, respectively. As a result, our findings suggest that, by Mulliken population analysis (MPA), frontier orbital analysis, and electrostatic potential (EP) analysis based on B3LYP/6-31G calculations, the chemical stability, water resistance, and shearing viscosity of the oxidized modified starch-based adhesives are uniformly improved and corresponding difference for each property presents an identical order: the oxidized grafted cross-linked starch-based adhesive $>$ the oxidized grafted starch-based adhesive $>$ the oxidized starch-based adhesive, which is well consistent with experimental results.
\end{abstract}

\section{Introduction}

Starch, the most important energy source and most abundant carbohydrate as common biopolymers, possesses inexpensive and naturally renewable characteristics and is extensively applied in the diverse areas of polymer science [1-6]. At present, starch has been used successfully as an additive in papermaking, as well as an adhesive [7]. In recent years, with the enhancement of people's awareness to environmental protection and health, the starch-based adhesive has been considered as the most potential adhesive in the application and development [8-12]. However, compared with the "native starch" extracted directly from the plant, the so-called "modified starch" with one or more chemical modifications can reach specific properties $[13,14]$. Therefore, a large number of studies have been devoted to exploring the effect of the modification methods on the properties of the starchbased adhesives [15-17], such as gelatinization [18], oxidizing [19], cross-linking [20], and grafting [21]. Meanwhile, the physical properties of these modified starch-based derivatives have also been widely discussed $[22,23]$, indicating lower hydrophilicity and higher intensity.

Among a great deal of investigations of the modified starches, those after chemical modification like the oxidation attract our great interest, in which carboxyl and carbonyl functional groups can be introduced into the starch chains [24]. The modification had been studied in detail by Wing and Parovuori et al. $[25,26]$ who proposed that chemical stability, water resistance, and shearing viscosity are improved. Nevertheless, it should be pointed out that a theoretical investigation is very important in understanding the origin of the characteristic variation so as to conclude the regular reasons. Unfortunately, to the best of our knowledge, no theoretical study has reported the oxidized derivatives with different properties so far. Thus, in this paper, we would complete a detailed computational investigation to analyze the properties of three types of oxidized modified starch-based adhesives, aiming at the origin and difference of chemical 


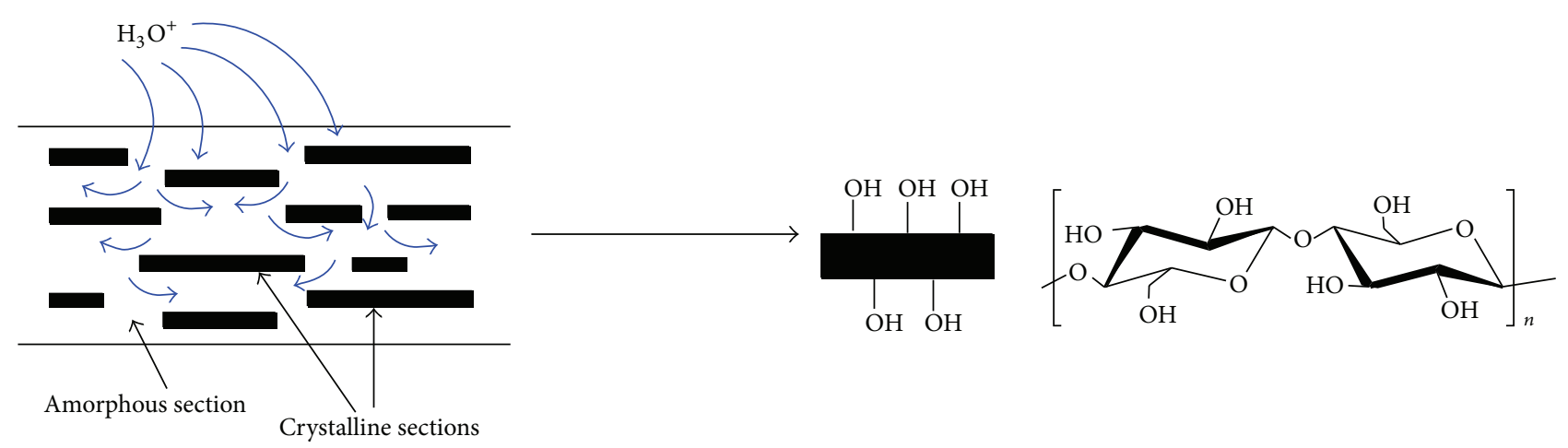

SCHEME 1: Representation of the acid hydrolysis of cellulose and chemical structure of cellulose.

stability, water resistance, and shearing viscosity. Note that our theoretical investigation should be very reasonable for this studied system because of the existence of some small glucopyranose residues derived from the partial breakage of starch molecular chains by acid hydrolysis, as visualized in Scheme 1. Consequently, our calculations presented here can provide comprehensive and authentic information, thereby giving a suitable explanation to the experimental results; meanwhile, the results obtained can also predict the properties of analogous species for some known and/or as yet unknown systems.

\section{Computational Methods}

All equilibrium geometries in this paper have been fully optimized at the AM1 semiempirical level without any symmetry restriction [27], which is very favorable to treat the macromolecule. For each optimized stationary point, vibrational frequency analysis obtained at the same theoretical level was performed to determine its character as minima (zero imaginary frequencies). To obtain more reliable theoretical data, the geometries of three types of key starch molecules (the oxidized starch molecule, the oxidized grafted starch molecule, and the oxidized grafted cross-linked starch molecule, resp.) were further optimized at the DFTB3LYP [28, 29] level with the 6-31G basis set (B3LYP/6$31 G$ ) by using the AM1 semiempirical optimized geometries. All calculations reported here have been carried out with Gaussian 03 [30] program package.

To describe the oxidized starch-based adhesives' chemical stability preventing degradation due to oxygen erosion, the mean square displacement (MSD) was performed via the 10 ps total simulation with time step of $0.5 \mathrm{fs}$ which is defined as

$$
\operatorname{MSD}=\left\langle\left[r_{i}(t)-r_{\mathrm{i}}(0)\right]^{2}\right\rangle,
$$

where $r_{i}(t)$ is the displacement vector at $t$ time and \langle\rangle is the ensemble average.
The increase of MSD with time is related to the diffusion coefficient $D$ [33]:

$$
\begin{gathered}
D=\frac{N_{a}}{6} \lim _{t \rightarrow \infty} \frac{d}{t} \sum_{i=1}^{N_{a}}\left\langle\left[r_{i}(t)-r_{i}(0)\right]^{2}\right\rangle \\
D=\frac{N_{a}}{6} \lim \frac{d}{d_{t}} \sum_{i=1}^{N_{a}} \mathrm{MSD},
\end{gathered}
$$

where $N_{a}$ is the number of diffusive atoms in the system; in Forcite module, the MSD is already averaged over all atoms and the relationship between MSD and time has been fitted as a straight line: $y=a x+b ; D$ then follows as

$$
D=\frac{a}{6}
$$

Finally, shearing viscosity $(\eta)$ was calculated to simulate the shearing for the oxidized starch-based adhesives. Shear rate as an input to the simulation was set as $0.1 \mathrm{~s}^{-1}$. Herein, shearing viscosity is defined as

$$
\eta=\frac{\sigma}{\gamma}
$$

where $\sigma$ is the shear stress and $\gamma$ is the shear rate.

All MD simulation was performed under the NVE ensemble with the COMPASS force field at $298 \mathrm{~K}$ utilizing Forcite modules in the version of Materials Studio 6.0 [34].

\section{Results and Discussion}

We have carried out a series of computational investigations at the AM1 level based on the constructed model (Starch$\mathrm{OH})_{n}$ and comparatively discovered that the analogous charges distribution appears in the different starch molecules when $n$ is designated from 7 to 20 . As we all know, it is difficult to carry out a DFT calculation for the starch system due to the extremely expensive computational price. Accordingly, it is very rational for our research objects when $n=8-9$ to be investigated by DFT-B3LYP method as an illustrative example in this paper, so as to explore how and to what extent the 


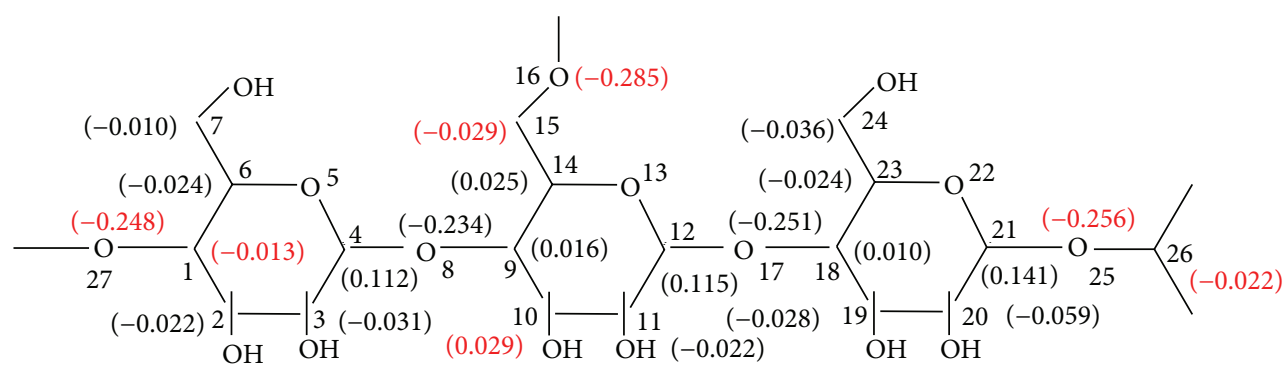

(a)

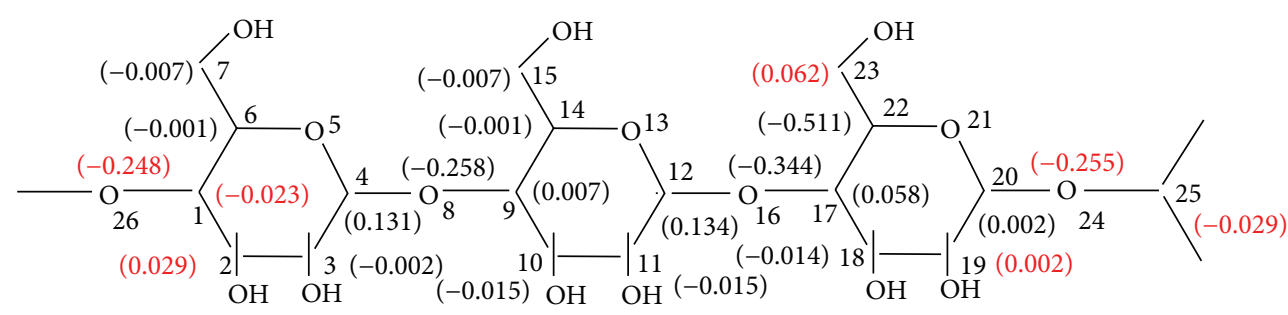

(b)

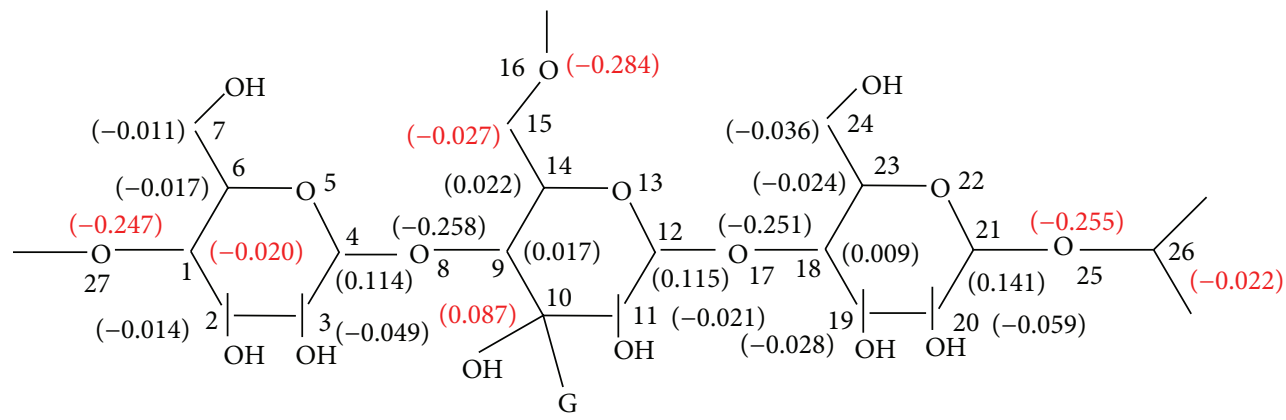

(c)

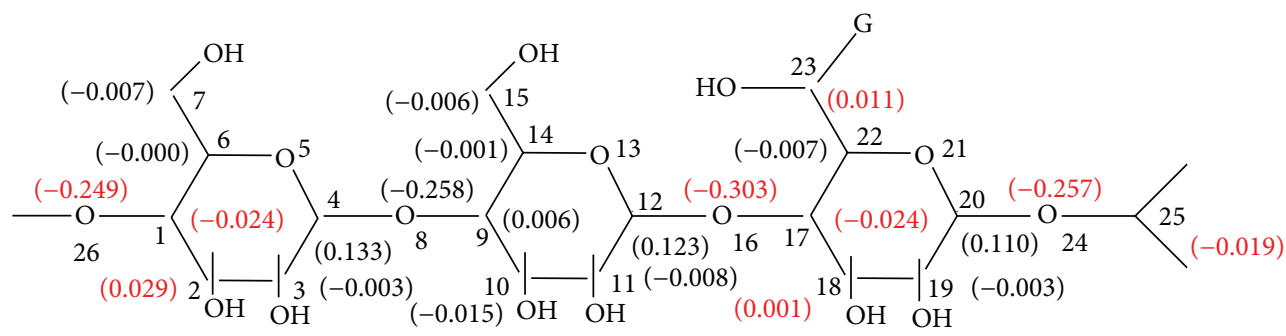

(d)

Scheme 2: Mulliken charges population of the main atoms in the starch molecules at the AM1 semiempirical level. G: vinyl alcohol group. (a) is the amylopectin molecule; (b) is the amylose molecule; (c) is the grafted amylopectin molecule; and (d) is the grafted amylose molecule.

small molecules derived from the oxidized starches influence the properties of the modified starch-based adhesives, such as chemical stability, water resistance, and shearing viscosity, although only few amount of the small molecules can be detected in the starch-based adhesives after the oxidization.

\subsection{Formation and Structure of the Oxidized Starch Molecule.} The results of MPA are listed in Scheme 2. As shown in Scheme 2(a), the charges located on $\mathrm{O}^{16}, \mathrm{O}^{25}$, and $\mathrm{O}^{27}$ atoms of the amylopectin molecule are $-0.285,-0.256$, and
-0.248 a.u., respectively. Note that charges of the carbon atoms associated with the above-mentioned oxygen atoms were clearly negative, taking (a.u.) -0.029 on $\mathrm{C}^{15},-0.022$ on $\mathrm{C}^{26}$, and -0.013 on $\mathrm{C}^{1}$, respectively. It can be strongly suggested that the starch crystalline structures can be largely damaged due to the bursting of the granule structures presented in the breakage of molecular chains taking place in the $\mathrm{C}^{1}-\mathrm{O}^{27}, \mathrm{C}^{15}-\mathrm{O}^{16}$, and $\mathrm{C}^{26}-\mathrm{O}^{25}$ bonds when the starch pastes were oxidized. Comparatively, in the amylose molecule as observed in Scheme 2(b), the intermolecular 


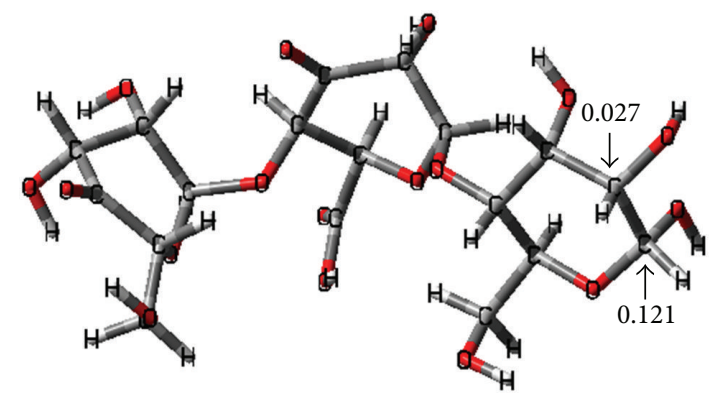

(a)

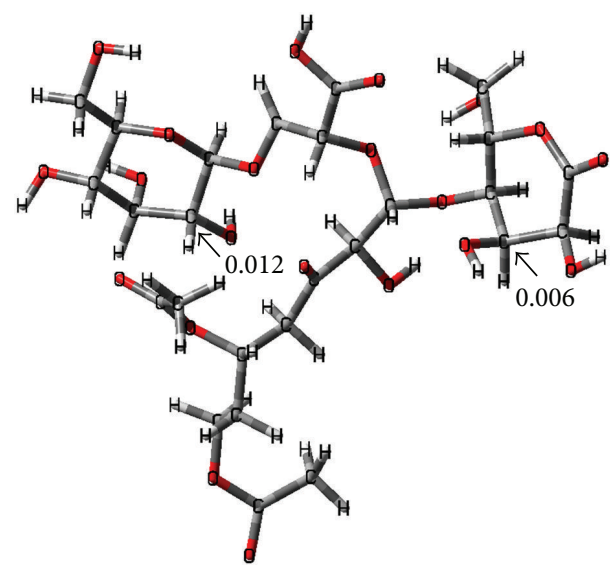

(c)

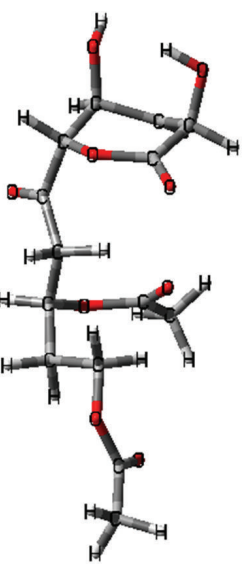

(d)

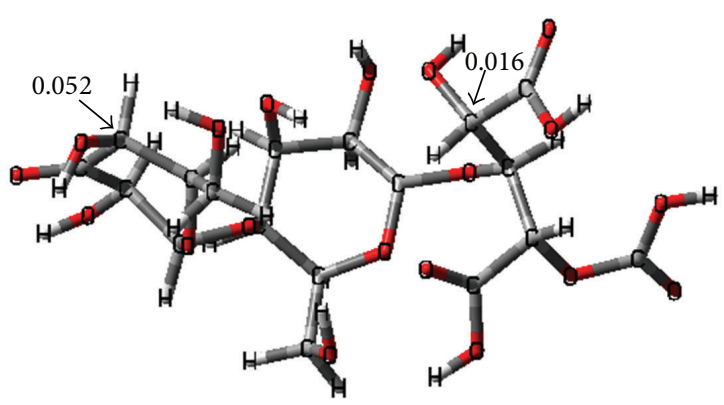

(b)

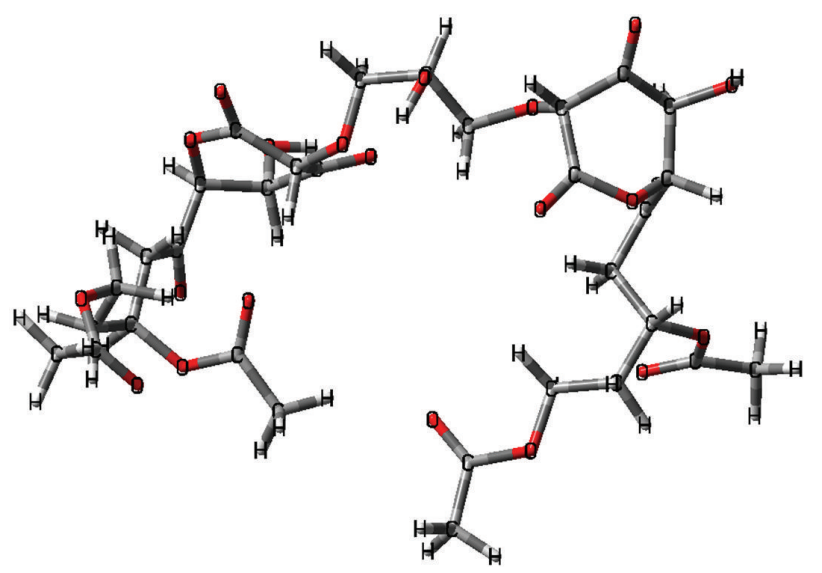

(e)

FIGURE 1: B3LYP/6-31G computational models of the oxidized modified starch molecules. (a) and (b) are the oxidized starch molecules, respectively; (c) and (d) are the oxidized grafted starch molecules, respectively; and (e) is the oxidized grafted cross-linked starch molecule. Additionally, some main Mulliken charges population in the molecules (a), (b), and (c) were indicated by arrow.

breakage should happen in the bonds $\mathrm{C}^{1}-\mathrm{O}^{26}$ and $\mathrm{C}^{25}-\mathrm{O}^{24}$, respectively. Those support that hydroxyl groups in starch, primarily at the C-2, C-3, and C-6 positions, are transformed into carbonyl or carboxyl groups via oxidation [35, 36]. Therefore, the original starch pastes after the oxidization, regardless of the amylopectin or amylose, should all cover three-polysaccharide molecules due to depolymerization of the molecular chains, which decreased the molecular weight. Obviously, the hydroxyl groups in the starch also decreased with oxidation, which can effectively improve the water resistance of the adhesive. Moreover, based on the consideration of dual effect from the charges distribution and the steric effect, the $\mathrm{C}^{10}$ atom in the amylopectin molecule and the $\mathrm{C}^{2}, \mathrm{C}^{19}$, and $\mathrm{C}^{23}$ atoms in the amylose molecule with certain amount of positive charges should be the most active sites during the oxidization. It means that further oxidization can make the hydrogen bonds between the starch chains weakened, showing the oxidization of the hydroxyl groups associated with $\mathrm{C}^{10}, \mathrm{C}^{19}, \mathrm{C}^{23}$, and $\mathrm{C}^{2}$ atoms, so leading to higher thermoplasticity and hydrophobicity for the starch pastes. Here, the hydroxyl groups bonded $\mathrm{C}^{2}, \mathrm{C}^{10}$, and $\mathrm{C}^{19}$ are oxidized to the ketone groups while the hydroxyl groups bonded $\mathrm{C}^{23}$ is did the carboxyl groups; namely, hybridization state of the $C^{10}, C^{19}, C^{23}$, and $C^{2}$ atoms was changed from $\mathrm{sp}^{3}$ to $\mathrm{sp}^{2}$, inducing further molecular stability. Additionally, the ketone group neighbored with $\mathrm{C}^{19}$ atom is oxidized to carboxyl group. As a result, the net proportion between the carboxyl and the ketone group is $4: 3$, which is consistent with the results measured in experiment [19], finding that the amount of carboxyl groups exceeds that of ketone groups. Moreover, it can be seen that there are two parts with positive charges indicated by arrow as shown in Figure 1 that are presented in the oxidized molecules (a) and (b), respectively, which is easy to be further oxidized. Here, (a) involves the formation of two carboxyl groups via oxygenation process, while in (b) two hydroxyl groups are firstly oxidized to form corresponding ketone groups; subsequently one ketone group originated from the oxidized hydroxyl group just now and another neighboring ketone group; both are further oxidized to yield two carboxyl groups. Thus, when the oxidized starches are deeply oxidized, the amount of carboxyl groups will increase progressively as compared to that of ketone groups, reflecting that the crystalline structures of the starch granules are further damaged. This is in good agreement with the experimental results [26]. Therefore, with the increase of the oxidants added to the reactions, more carboxyl groups being available in starch increase the hydration capacity of starch pastes and result in formation of more glucose residues which contains a lot of inorganic components. Determination of the Oxidized Grafted Cross-Linked Starch 
Molecule. As shown in Scheme 2, on basis of consideration of the steric effect, the maximal positive charges distributions are located on $\mathrm{C}^{10}$ (0.029 a.u.) in the amylopectin molecule and on $C^{23}$ (0.062 a.u.) in the amylose molecule, respectively. It means that the $\mathrm{C}^{10}$ and $\mathrm{C}^{23}$ positions of the species are much easier to be attacked by nucleophiles. So, the vinyl alcohol, acting as a kind of stronger nucleophile molecule, firstly attaches to $\mathrm{C}^{10}$ and $\mathrm{C}^{23}$, followed by concerted oxygenation, to generate the oxidized grafted starch molecule in which the obtained proportion between the carboxyl and the ketone group is closely equal to $4: 3$ [37]. Thus, compared with the single oxidized starch pastes, the starch pastes after grafted oxidized treatment do not essentially change the proportion, in turn keeping the same values. Furthermore, in the molecule (c), there are two parts with positive charges indicated by arrow as shown in Figure 1, which imply the further oxygenation of the hydroxyl groups. More important, with further oxygenation of the oxidized grafting starch molecule, the amount of ketone groups is increasing; namely, the water resistance of corresponding starch emulsion is increased because of presence of a great deal of hydrophobicity groups. It is presumable that molecule (c) is instable and thus unfavorable model in theoretics to construct geometry of the oxidized grafted cross-linked starch molecule. However, in the molecule (d), there is no part with positive charges; that is, the molecule (d) is not further oxidized and thus considered as a steady molecule. As a result, we have presented rationally geometry of the oxidized grafted cross-linked starch molecule (e) on the basis of the structure of molecule (d) via the cross-link by epoxychloropropane so as to compare its characteristics with the other modified starch molecules [38], which can scientifically provide comprehensive and authentic information, thereby interpreting the difference in properties of the different oxidized modified starch adhesives presented here.

3.3. Chemical Stability of Three Types of Oxidized StarchBased Adhesives. According to the molecular orbital theory [39-43], chemical stability of all modified starch molecules is very high because the energy values of corresponding $\mathrm{HOMO}$ and LUMO are negative. Moreover, the difference in stability is easily understood in terms of the HOMO (Lewis base)-LUMO (Lewis acid) interaction; namely, a smaller HOMO-LUMO gap $(\Delta E)$ helps in more electrotransition in general, so it is unfavorable for the formation of a Lewis steady molecule. Our theoretical result indicates that $\Delta E$ value of the oxidized starch molecule is less than that of the oxidized grafted starch molecule as shown in Table 1. Consequently, it is reasonable that the chemical stability of the oxidized grafted starch molecule is higher than that of the oxidized starch molecule. In other words, the composite modified starch-based adhesive possesses higher chemical stability than the single modified starch-based adhesive, which are analogues to the results of the graft modification enhanced the thermal stability [32]. Moreover, as mentioned before (see Section 3.1), the hydroxyl groups associated with the carbons with positive charges indicated by arrow in molecule (b) are oxidized to form one ketone group and three carboxyl groups, respectively, as compared with those in molecule (a) that contains two ketone groups and one carboxyl group, respectively. Therefore, the water resistance of the starch paste associated with molecule (a) was improved and thus itself chemical stability for corresponding adhesive was rationally increased. This is fully confirmed by our theoretical calculations. As shown in Table 1, there is the order of $\Delta E_{(\mathrm{b})}<\Delta E_{(\mathrm{a})}$. Furthermore, compared to the modified starch molecules (a), (b), and (c), it can be seen that the oxidized grafted cross-linked starch molecule (e) presents less value for $\Delta E$ gap. This seems plausible that the chemical stability of the composite modified starchbased adhesives is lower than that of the other modified starch-based adhesives. In fact, based on the electrostatic potential (EP) analysis, we have found that chemical stability of the oxidized grafted cross-linked starch-based adhesive itself is also related to corresponding molecules' watersolubility, which is mentioned in Section 3.4. Moreover, diffusion coefficient of oxygen molecules in the modified starch-based adhesive might give us a reasonable explanation why chemical stability of the composite modified adhesive is higher than that of the single modified cases with respect to preventing degradation according to the simulation of oxygen erosion. The relationships between MSD and time are shown in Figure 2. The diffusion coefficients $\left(\mathrm{cm}^{2} \mathrm{~s}^{-1}\right)$ of oxygen in the modified starches equal $2.1 \times 10^{-5}$ (a), 2.1 $\times 10^{-5}(\mathrm{~b}), 1.7 \times 10^{-5}$ (c), $1.8 \times 10^{-5}(\mathrm{~d})$, and $1.6 \times 10^{-6}$ (e), respectively. Therefore, the composite modified starchbased adhesive with the higher stability due to better oxygen resistance performance can be ascribed to the lower diffusion coefficient of oxygen molecules.

3.4. Water Resistance and Shearing Viscosity of Three Types of Oxidized Starch-Based Adhesives. As known, the electrostatic potential (EP) acted as the most informative property can describe visually charges distribution in molecule, favoring the determination of active regions of corresponding molecule. In this paper, the models as shown in Figure 3, showing the EP (blue = positive, red = negative) mapped onto the van der Waals surface, are reported as the representative examples, displaying that the largest positive density (deepest blue) is concentrated on the oxidized grafted cross-linked starch molecule (e), as compared with the other oxidized modified starch molecules (a), (b), (c), and (d), and a decreasing trend can be found in the order of $(\mathrm{e})>(\mathrm{c}) \approx$ $(\mathrm{d})>(\mathrm{a}) \approx(\mathrm{b})$. Thus, the oxidized grafted cross-linked starch molecule is much easier to be attacked by water molecule; namely, chemical stability of the oxidized grafted cross-linked starch-based adhesive is greatly high because more water enter and combine. Nevertheless, as shown in Figure 3, the oxidized grafted cross-linked starch molecule's surface is easier to be hydrated, as compared to the oxidized starch molecule taking place in molecule's interior and the oxidized grafted starch molecule occurred in molecule's interior and surface. In other words, with the rising of temperature, the water molecules bonded the oxidized grafted crosslinked starch molecule will be easier to be lost because the interaction between them only exists at the molecule's 

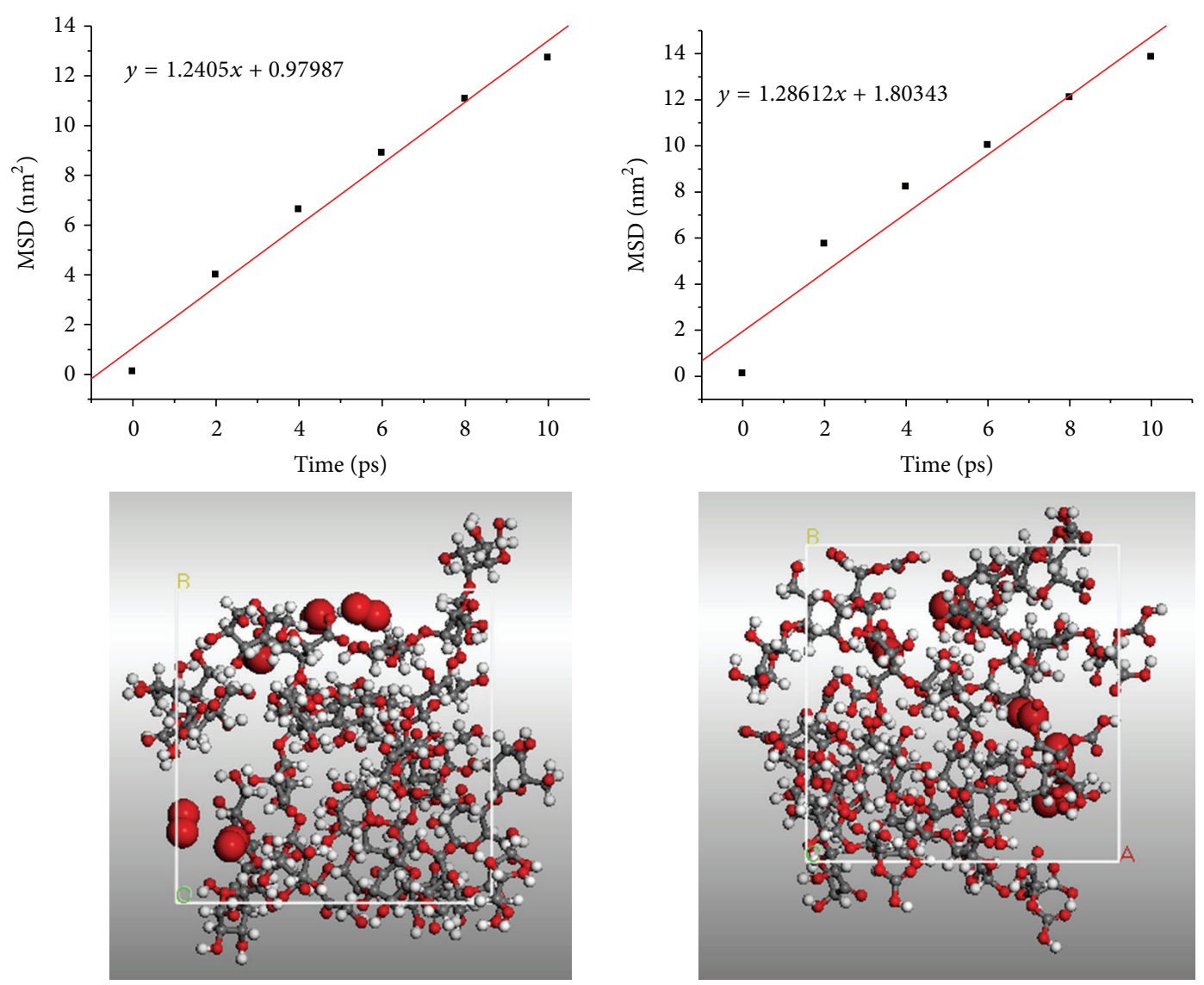

(a)

(b)
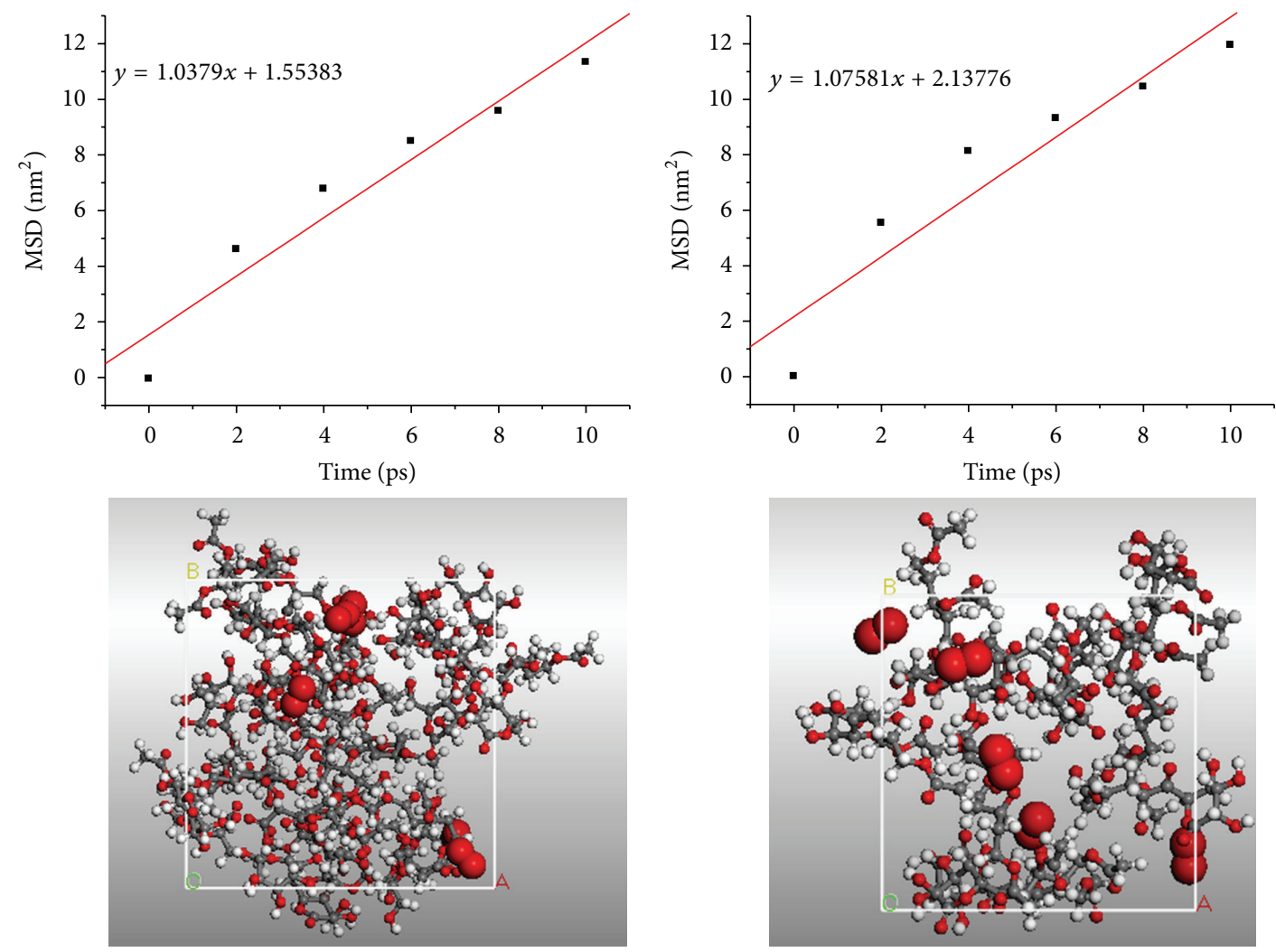

(c)

(d)

Figure 2: Continued. 

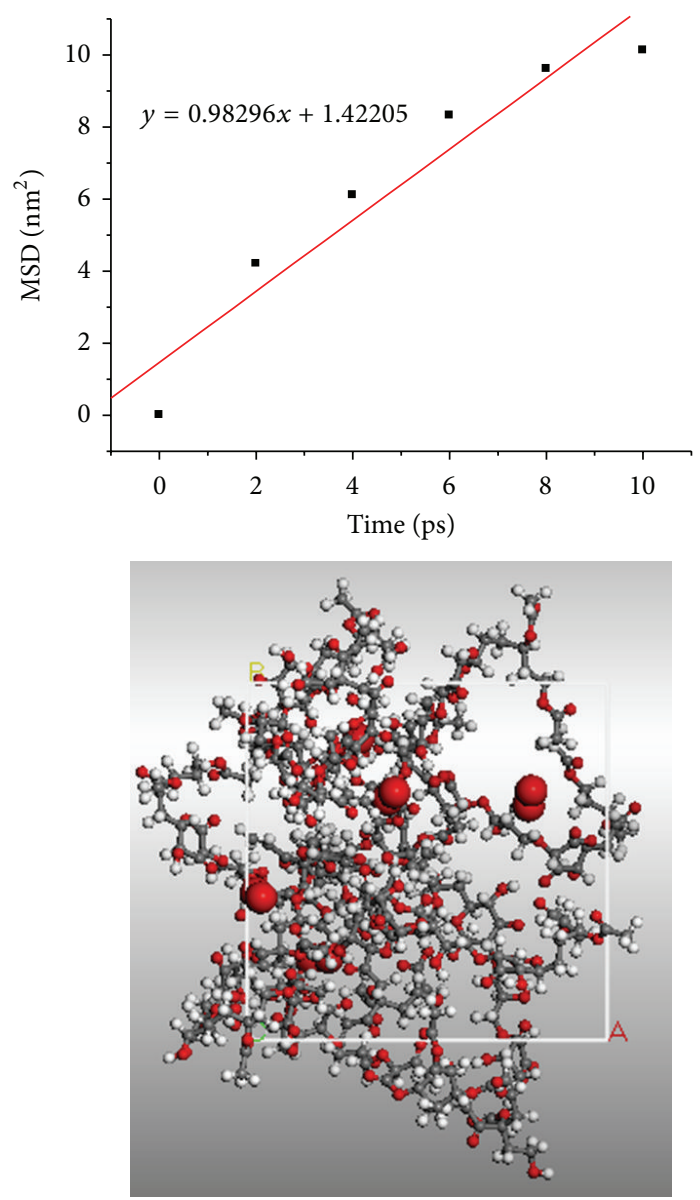

(e)

FIGURE 2: The relationship between MSD and time corresponding to annealed amorphous cell embraced five oxygen molecules in ten oxidized modified starch molecules. (a) and (b) are cases of the oxidized starch molecules, respectively; (c) and (d) are cases of the oxidized grafted starch molecules, respectively; and (e) is case of the oxidized grafted cross-linked starch molecule.

TABLE 1: Orbital energies (a.u.), dipole moment (D), viscosity (MPa s), and shear stress (MPa) of the oxidized modified starch molecules.

\begin{tabular}{|c|c|c|c|c|c|}
\hline & $\begin{array}{l}\text { Oxidized starch } \\
\text { molecule (a) }\end{array}$ & $\begin{array}{l}\text { Oxidized starch } \\
\text { molecule (b) }\end{array}$ & $\begin{array}{c}\text { Oxidized grafted } \\
\text { starch molecule (c) }\end{array}$ & $\begin{array}{l}\text { Oxidized grafted } \\
\text { starch molecule (d) }\end{array}$ & $\begin{array}{l}\text { Oxidized grafted } \\
\text { cross-linked starch } \\
\text { molecule (e) }\end{array}$ \\
\hline HOMO & -0.3972 & -0.3364 & -0.3957 & -0.4027 & -0.3927 \\
\hline LUMO & -0.0169 & -0.0089 & -0.0008 & -0.0132 & -0.0152 \\
\hline$\Delta E=E_{\mathrm{LUMO}}-E_{\mathrm{HOMO}}$ & 0.3803 & 0.3275 & 0.3949 & 0.3895 & 0.3775 \\
\hline Dipole moment & 2.3485 & 1.3664 & 1.8523 & 2.6105 & 5.8061 \\
\hline Viscosity & 3.897 & 1.370 & 3.587 & 7.342 & 58.190 \\
\hline Shear stress & \multicolumn{2}{|c|}{$0.5267[0.5]^{\mathrm{a}}$} & \multicolumn{2}{|c|}{$1.0929\{1.12 \pm 0.07\}^{\mathrm{b}}$} & $\begin{array}{l}5.8190[5.6]^{\mathrm{a}} \\
\{5.45 \pm 0.06\}^{\mathrm{b}}\end{array}$ \\
\hline
\end{tabular}

${ }^{a}$ Reference [31].

${ }^{\mathrm{b}}$ Reference [32].

surface. This strongly supports that the water resistance of the oxidized grafted cross-linked starch-based adhesives will be progressively improved with rising of the temperature. So, it is reasonable if we consider the decrease in water resistance for the oxidized modified starch-based adhesives presented here, exhibiting the following order: oxidized grafted cross-linked starch-based adhesive $>$ the oxidized grafted starch-based adhesive $>$ the oxidized starch-based adhesive, in excellent agreement with Zhang et al's conclusion that water resistance of the starch-based adhesive was significantly improved via the graft modification of oxidized starch [32].

Furthermore, a common use of the shearing simulation is to calculate and provide a wealth of insights into the shearing viscosity of the liquid. As shown in Table 1, the shear stress 


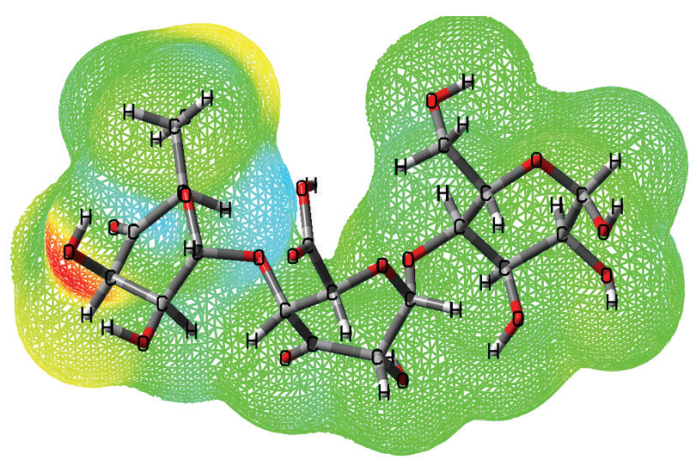

Red color for the negative and blue color for the positive charge

(a)

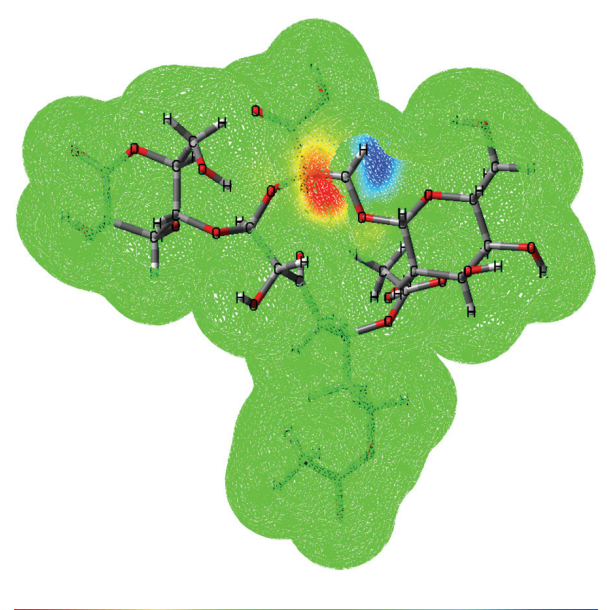

Red color for the negative and blue color for the positive charge

(c)

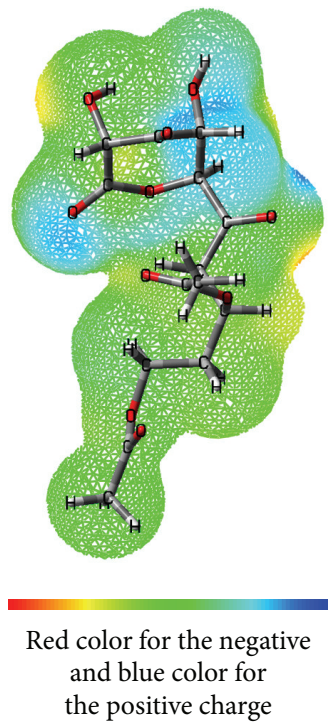

(d)

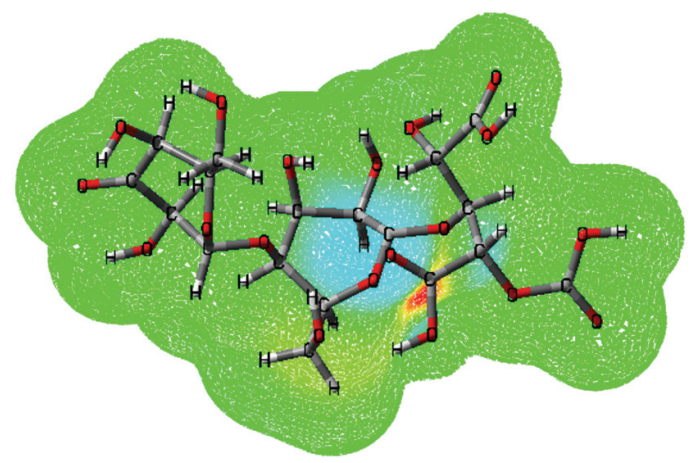

Red color for the negative and blue color for the positive charge

(b)

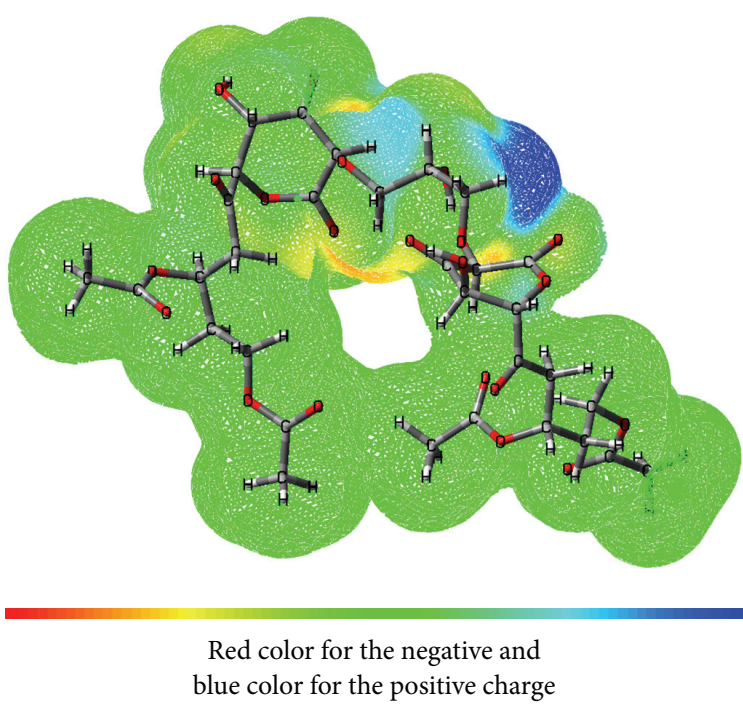

(e)

FIGURE 3: Electrostatic potential (EP) of the oxidized modified starch molecules at the B3LYP/6-31G level of theory. (a) and (b) are the oxidized starch molecules, respectively; (c) and (d) are the oxidized grafted starch molecules, respectively; and (e) is the oxidized grafted cross-linked starch molecule.

data for those oxidized starch-based adhesives are found to be $0.5267,1.0929$, and 58.190 MPa for the (a) + (b), (c) + (d), and (e) residues, respectively, in excellent agreement with our previous experiential predictions $[31,32]$. According to the highviscosity adhesive emulsion that prevented the spreading and permeation of the adhesive emulsion on the material surface [44], we suggest that the difference of shearing viscosity for the modified starch-based adhesives should be the oxidized grafted cross-linked starch-based adhesive $>$ the oxidized grafted starch-based adhesive $>$ the oxidized starch-based adhesive, which is in good agreement with the experimental results [23]. Moreover, the modified starch-based adhesives are very polarizable as revealed by corresponding EP and thus very sensitive to mutual polarization effects. This is fully confirmed by our theoretical calculations. For instance, the dipole moments (D) obtained for the modified starch molecules are 2.3485 (a), 1.3664 (b), 1.8523 (c), 2.6105 (d), and 5.8061 (e), respectively, as listed in Table 1. Thus, it is reasonable for the above-mentioned decrease order in shearing viscosity for the oxidized modified starch-based adhesives. Evidence also supports the conclusion that the higher polarization resulted in the higher shear stress [45].

\section{Conclusions}

In the present work, a detailed theoretical investigation has been performed to characterize formation of the small molecules from the oxidized modified starch-based adhesives and rationally explain corresponding adhesives' origin and different in chemical stability, water resistance, and shearing viscosity. With the above analysis in mind, some intriguing results were elicited as follows: (1) the small glucose molecules derived from the partial breakage of starch molecular chains in the oxidized modified starches can determine the properties of the corresponding adhesives; 
(2) structural destruction in the starch-based adhesives was very important to change the chemical stability; namely, the more serious destruction made in crystalline regions, the better chemical stability appeared; (3) based on the Mulliken population analysis (MPA), the frontier orbital analysis, and the electrostatic potential (EP) analysis, respectively, we have confirmed that chemical stability, water resistance, and shearing viscosity of three types of oxidized modified starchbased adhesives are uniformly improved and presented an identical order of the oxidized grafted cross-linked starchbased adhesive $>$ the oxidized grafted starch-based adhesive $>$ the oxidized starch-based adhesive, which is well consistent with available experimental results.

\section{Competing Interests}

The authors declare that they have no competing interests.

\section{Acknowledgments}

The project was supported by Fundamental Research Funds for the Central Universities (zyp2015018, zyz2011064), Natural Science Foundation of China (51563022), and Gansu National Science Supported Planning Projects (1504GKCA093).

\section{References}

[1] M. N. Belgacem and A. Gandini, Monomers, Polymers and Composites from Renewable Resources, Elsevier, Amsterdam, The Netherlands, 2008.

[2] J. M. V. Blanshard, "Starch granule structure and function: a physicochemical approach," in Starch: Properties and Potential, T. Galliard, Ed., John Wiley \& Sons, Chichester, UK, 1987.

[3] N. Wang, J. G. Yu, and X. F. Ma, "Preparation and characterization of thermoplastic starch/PLA blends by one-step reactive extrusion," Polymer International, vol. 56, no. 11, pp. 1440-1447, 2007.

[4] P. Tomasik and C. H. Schilling, "Chemical modification of starch," Advances In Carbohydrate Chemistry And Biochemistry, vol. 59, pp. 175-403, 2004.

[5] C. Seidel, W.-M. Kulicke, C. Heß, B. Hartmann, M. D. Lechner, and W. Lazik, "Synthesis and characterization of cross-linked carboxymethyl potato starch ether gels," Starch-Staerke, vol. 56, no. 5, pp. 157-166, 2004.

[6] M. B. Cardoso, J.-L. Putaux, D. Samios, and N. P. da Silveira, "Influence of alkali concentration on the deproteinization and/or gelatinization of rice starch," Carbohydrate Polymers, vol. 70, no. 2, pp. 160-165, 2007.

[7] A. J. F. Carvalho, "Starch: major sources, properties and applications as thermoplastic materials," in Monomers, Polymers and Composites from Renewable Resource, M. N. Belgacem and A. Gandini, Eds., Elsevier, Amsterdam, The Netherlands, 2008.

[8] S. Chattopadhyay, R. S. Singhal, and P. R. Kulkarni, "Optimisation of conditions of synthesis of oxidised starch from corn and amaranth for use in film-forming applications," Carbohydrate Polymers, vol. 34, no. 4, pp. 203-212, 1997.

[9] J. M. Fang, P. A. Fowler, J. Tomkinson, and C. A. S. Hill, "The preparation and characterisation of a series of chemically modified potato starches," Carbohydrate Polymers, vol. 47, no. 3, pp. 245-252, 2002.

[10] R. Felicidad and H. R. Yrjö, "Gelatinization and freezeconcentration effects on recrystallization in corn and potato starch gels," Carbohydrate Research, vol. 343, no. 5, pp. 903-911, 2008.

[11] P. Forssell, A. Hamunen, K. Autio, P. Suortti, and K. Poutanen, "Hypochlorite oxidation of barley and potato starch," StarchStarke, vol. 47, no. 10, pp. 371-377, 1995.

[12] J. J. G. van Soest, H. Tournois, D. de Wit, and J. F. G. Vliegenthart, "Short-range structure in (partially) crystalline potato starch determined with attenuated total reflectance Fouriertransform IR spectroscopy," Carbohydrate Research, vol. 279, pp. 201-214, 1995.

[13] M. Zdanowicz, B. Schmidt, and T. Spychaj, "Starch graft copolymers as superabsorbents obtained via reactive extrusion processing," Polish Journal of Chemical Technology, vol. 12, no. 2, pp. 14-17, 2010.

[14] S.-D. Zhang, Y.-R. Zhang, J. Zhu, X.-L. Wang, K.-K. Yang, and Y.-Z. Wang, "Modified corn starches with improved comprehensive properties for preparing thermoplastics," Starch/Staerke, vol. 59, no. 6, pp. 258-268, 2007.

[15] R. Hoover and F. Sosulski, "Effect of cross-linking on functional properties of legume starches," Starch, vol. 38, no. 5, pp. 149-155, 1986.

[16] J. Gao, J. Yu, W. Wang, L. Chang, and R. Tian, "Graft copolymerization of starch-AN initiated by potassium permanganate," Journal of Applied Polymer Science, vol. 68, no. 12, pp. 1965-1972, 1998.

[17] B. Z. Li, L. J. Wang, D. Li et al., "Physical properties and loading capacity of starch-based microparticles crosslinked with trisodium trimetaphosphate," Journal of Food Engineering, vol. 92, no. 3, pp. 255-260, 2009.

[18] J. S. Lee, R. N. Kumar, H. D. Rozman, and B. M. N. Azemi, "Flow behaviour of sago starch-g-poly(acrylic acid) in distilled water and $\mathrm{NaOH}$-effect of photografting," Carbohydrate Polymers, vol. 56, no. 3, pp. 347-354, 2004.

[19] T. Sugama, "Oxidized potato-starch films as primer coatings of aluminium," Journal of Materials Science, vol. 32, no. 15, pp. 3995-4003, 1997.

[20] T. Yoneya, K. Ishibashi, K. Hironaka, and K. Yamamoto, "Influence of cross-linked potato starch treated with $\mathrm{POCl} 3$ on DSC, rheological properties and granule size," Carbohydrate Polymers, vol. 53, no. 4, pp. 447-457, 2003.

[21] M. Çelik, "Preparation and characterization of starch-gpolymethacrylamide copolymers," Journal of Polymer Research, vol. 13, no. 5, pp. 427-432, 2006.

[22] C. G. Biliaderis, A. Lazaridou, and I. Arvanitoyannis, "Glass transition and physical properties of polyol-plasticized pullulan-starch blends at low moisture," Carbohydrate Polymers, vol. 40, no. 1, pp. 29-47, 1999.

[23] Z. D. Li, G. Y. Li, and M. Yu, Handbook of Modern Adhesive Technique, New Times Press, Beijing, China, 1st edition, 2002.

[24] K. Sangseethong, N. Termvejsayanon, and K. Sriroth, "Characterization of physicochemical properties of hypochlorite- and peroxide-oxidized cassava starches," Carbohydrate Polymers, vol. 82, no. 2, pp. 446-453, 2010.

[25] R. E. Wing and J. L. Willett, "Water soluble oxidized starches by peroxide reactive extrusion," Industrial Crops and Products, vol. 7, no. 1, pp. 45-52, 1997. 
[26] P. Parovuori, A. Hamunen, P. Forssell, K. Autio, and K. Poutanen, "Oxidation of potato starch by hydrogen peroxide," Starch, vol. 47, no. 1, pp. 19-23, 1995.

[27] M. J. S. Dewar, "The semiempirical approach to chemistry," International Journal of Quantum Chemistry, vol. 44, no. 4, pp. 427-447, 1992.

[28] P. J. Wilson and D. J. Tozer, "A Kohn-Sham study of the oxireneketene potential energy surface," Chemical Physics Letters, vol. 352, no. 5-6, pp. 540-544, 2002.

[29] Q. S. Li, X. D. Xu, and S. Zhang, "Predicting energies and geometries for reactions involved in atmosphere chemistry: a comparison study between hybrid DFT methods," Chemical Physics Letters, vol. 384, no. 1-3, pp. 20-24, 2004.

[30] M. J. Frisch, G. W. Trucks, H. B. Schlegel et al., Gaussian 03, Gaussian Inc., Pittsburgh, Pa, USA, 2003.

[31] Y. B. Wang and Q. Su, "Study on oxidation method of corn starch and characterization of high efficiency catalyst," Chemistry World, vol. 41, no. 6, pp. 306-308, 2000.

[32] Y. H. Zhang, L. L. Ding, J. Y. Gu, H. Y. Tan, and L. B. Zhu, "Preparation and properties of a starch-based wood adhesive with high bonding strength and water resistance," Carbohydrate Polymers, vol. 115, pp. 32-37, 2015.

[33] M. Meunier, "Diffusion coefficients of small gas molecules in amorphous cis-1,4-polybutadiene estimated by molecular dynamics simulations," The Journal of Chemical Physics, vol. 123, no. 13, Article ID 134906, 2005.

[34] H. Sun, "COMPASS: an ab initio force-field optimized for condensed-phase applications-overview with details on alkane and benzene compounds," The Journal of Physical Chemistry B, vol. 102, no. 38, pp. 7338-7364, 1998.

[35] D. Kuakpetoon and Y.-J. Wang, "Structural characteristics and physicochemical properties of oxidized corn starches varying in amylose content," Carbohydrate Research, vol. 341, no. 11, pp. 1896-1915, 2006.

[36] M. Kurakake, Y. Akiyama, H. Hagiwara, and T. Komaki, "Effects of cross-linking and low molecular amylose on pasting characteristics of waxy corn starch," Food Chemistry, vol. 116, no. 1, pp. 66-70, 2009.

[37] S. Duquesne, J. Lefebvre, R. Delobel, G. Camino, M. LeBras, and G. Seeley, "Vinyl acetate/butyl acrylate copolymers-part 1: mechanism of degradation," Polymer Degradation and Stability, vol. 83, no. 1, pp. 19-28, 2004.

[38] W. Yanbo, L. Chengfei, and H. Meina, "Synthesis and performance study of polybasic starch graft copolymerization function materials," Advanced Materials Research, vol. 79-82, pp. 43-46, 2009.

[39] R. A. Moss, M. Fedorynski, and W.-C. Shieh, "Unification of the carbenic selectivity spectrum. The ambiphilicity of methoxychlorocarbene," Journal of the American Chemical Society, vol. 101, no. 16, pp. 4736-4738, 1979.

[40] R. A. Moss and R. C. Munjal, "Differentiation of electrophilic and ambiphilic carbenes," Tetrahedron Letters, vol. 20, no. 49, pp. 4721-4724, 1979.

[41] N. P. Smith and I. D. R. Stevens, "Formation and reactions of chloro-methoxy- and -(2-methylpropoxy)-carbene," Journal of the Chemical Society, Perkin Transactions, vol. 2, no. 9, pp. 1298$1308,1979$.

[42] R. A. Moss, "Carbenic selectivity in cyclopropanation reactions," Accounts of Chemical Research, vol. 13, no. 2, pp. 58-64, 1980.
[43] W. M. Jones, R. A. LaBar, U. H. Brinker, and P. H. Gebert, "Generation and properties of 4,9- and 3,8-methano[11]annulenylidenes," Journal of the American Chemical Society, vol. 99, no. 19, pp. 6379-6391, 1977.

[44] Z. J. Wang, Z. F. Li, Z. B. Gu, Y. Hong, and L. Cheng, "Preparation, characterization and properties of starch-based wood adhesive," Carbohydrate Polymers, vol. 88, no. 2, pp. 699706, 2012.

[45] J. H. Sung, D. P. Park, B. J. Park, H. J. Choi, and M. S. Jhon, "Phosphorylation of potato starch and its electrorheological suspension," Biomacromolecules, vol. 6, no. 4, pp. 2182-2188, 2005. 

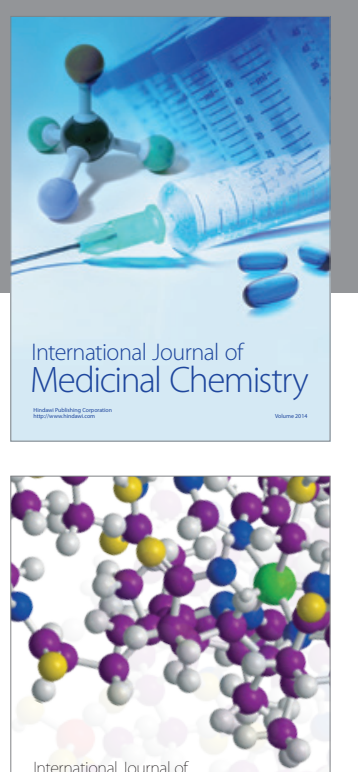

Carbohydrate Chemistry

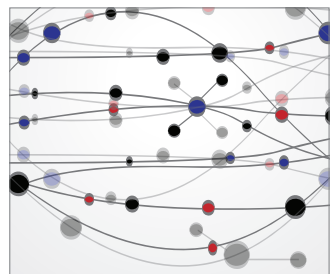

The Scientific World Journal
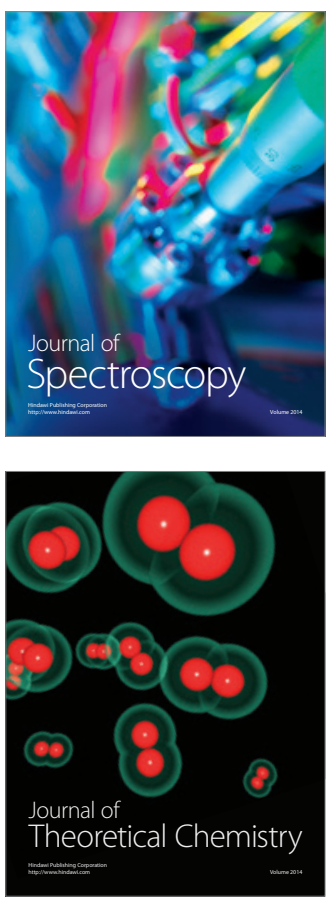
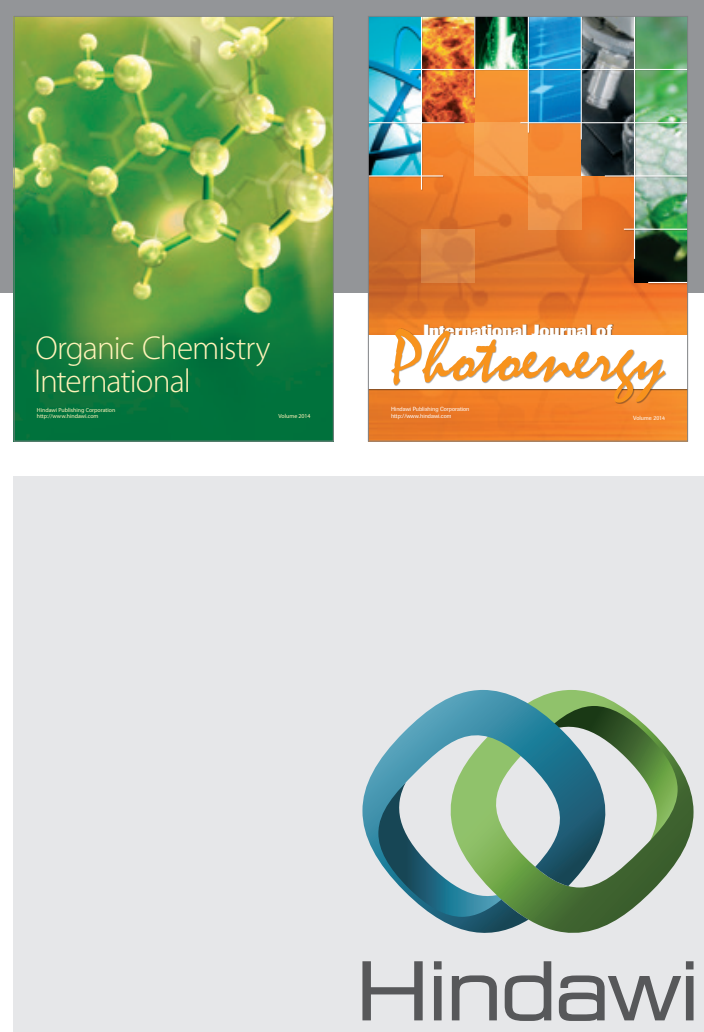

Submit your manuscripts at

http://www.hindawi.com

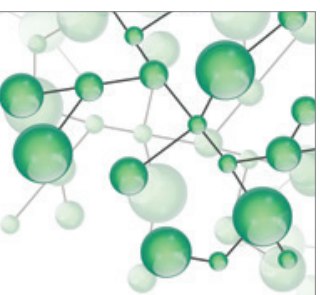

International Journal of

Inorganic Chemistry

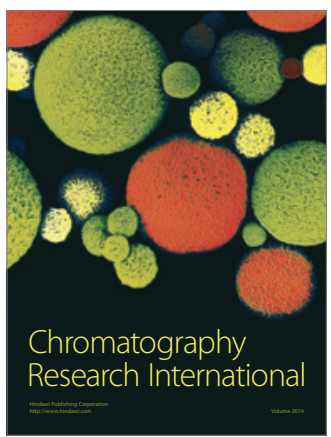

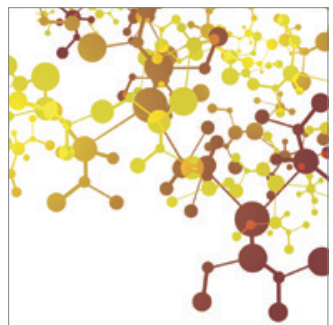

Applied Chemistry
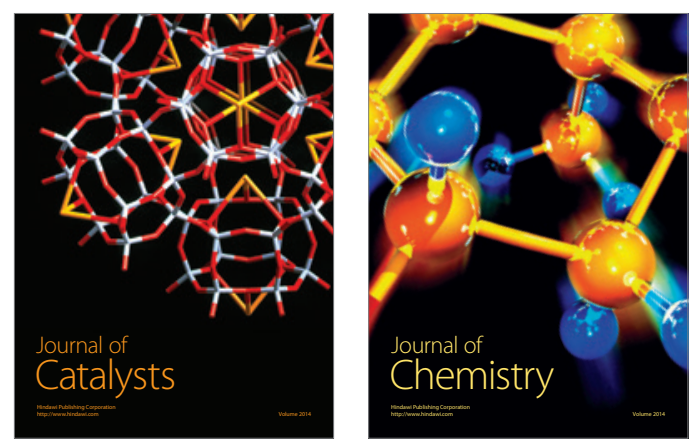
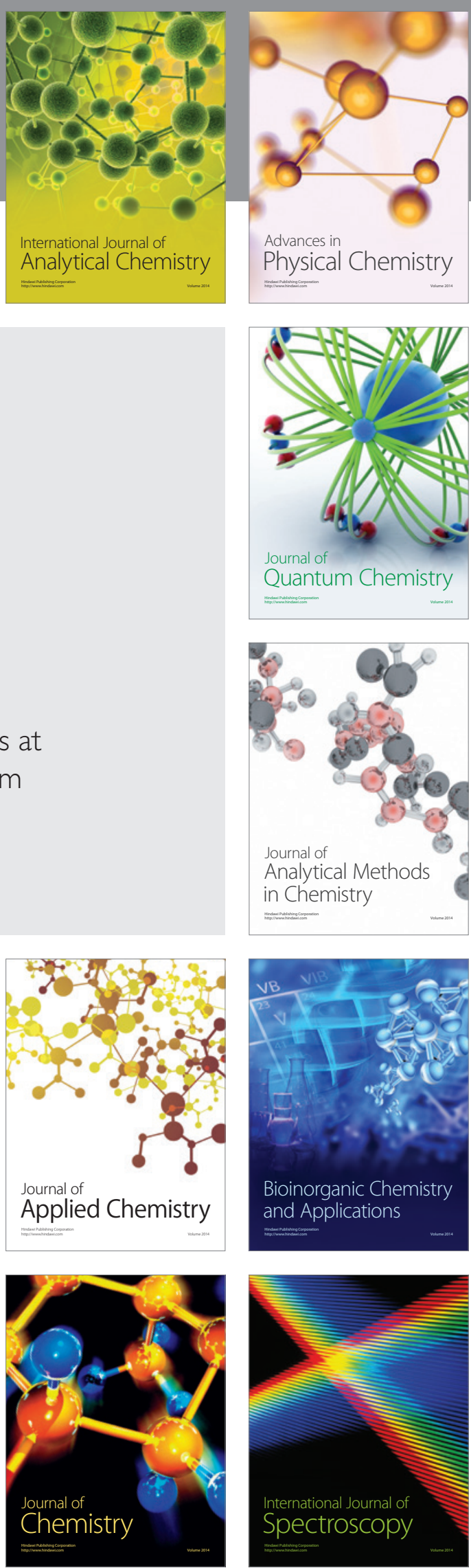